https://doi.org/10.29013/EJHSS-20-3-88-91

Voloshena Victoria Viktorovna, Doctor of Philosophy, Department Researcher

Mathematics and informatics education Institute of Pedagogy NAPN of Ukraine, Kiev, Ukraine E-mail:v.v.voloshena@gmail.com

\title{
MATHEMATICAL MODELING IN THE STRUCTURE OF STEM-LEARNING
}

\begin{abstract}
The article reveals the place of mathematical modeling in the new educational space of STEM-learning. Based on the disclosure of key components, it was concluded that mathematical modeling contributes to the formation of a system of natural mathematical knowledge, skills and abilities necessary in everyday life and future work, the development of constructive thinking as an integral part of the general culture of modern man.

Keywords: natural-mathematical education, key skills, competence, mathematical modeling, STEM-training.

Волочена Виктория Викторовна, канд. пед.наук, научный сотрудник отдела математического и информатического образования Института педагогики НАПН Украины, г. Киев, Украина E-mail:v.v.voloshena@gmail.com
\end{abstract}

\section{МАТЕМАТИЧЕСКОЕ МОДЕЛИРОВАНИЕ В СТУРУКТУРЕ STЕМ-ОБУЧЕНИЯ}

Аннотация. В статье раскрывается место математического моделирования в новом образовательном пространстве STEM-обучения. На основе раскрытия ключевых компонентов сделаны выводы, что математическое моделирование способствует формированию системы естественно-математических знаний, навыков и умений, необходимых в повсеАневной жизни и будущей трудовой Аеятельности, развитию конструктивного мышиения как неотъемлемой составмяющей общей культуры современного чемовека.

Ключевые слова: естественно-математическое образование, ключевые навыки, компетентность, математическое моделирование, STEM-обучение.

Мы прожили первые Авадцать мет XXI века, и становится очевидным, что весь мир вступим в эпоху бурных перемен, некую «эпоху турбументности», меняется все от геополитики до школы. Изменяются кяючевые навыки, опредемяющие успех чемовека: это уже не чтение, пись- мо и арифметика, а умение взаимодействовать с окружающими и работать в команде, лидерство, творческое и критическое мышиение, умение работать с изменениями и достигать результата. В наших обязанностях подготовить новое покомение Аля нового мира. 
Обучение математике тоже подвергается ряду изменений, касающихся и самих учебников и каАров, которые учат и которых обучают.

ОАним из направлений инновационного развития естественно-математического образования явцяется система обучения STEM, благодаря которой Аети развивают могическое мышление и техническую грамотность, учатся решать поставленные задачи. В Украине уже делаются первые шаги по внеАрению системы обучения STEM. Система уже закреплена на уровне законодательства Украины. ВнеАрение осуществляется в соответствии с образовательными законами и приказами МОН Украины.

STEM-обучение позволяет объеАинить научные методы, математическое моделирование, технологические приложения и инженерный Аизайн. Тем самым формируется инновационное критическое мышление, появмяется возможность и необходимость интегрированного обучения по темам, в рамках которого происходит активная коммуникация обучающихся и формируется новое образовательное пространство.

Решая проблему поиска научного метода, который бы позволил в рамках интегративных тенденций STEM обучения, учитывая глубокое единство содержания научных знаний при их формальном различии, обратим внимание именно на метоА моделирования. На роль математических моделей в реализации межпредметных связей математики и естествознания обращали внимание многие методисты и особо акцентировали внимание на том обстоятельстве, что обучение математическому моАелированию Аолжно осуществляться не только на уроках математики, но и в процессе обучения всем естественнонаучным Аисципиинам, преподающимся в средних общеобразовательных школах.

Использование этого метода к решению конкретных задач изложены в ряде известных монографий и учебных пособий. Вместе с тем, многие из них предполагают достаточно высокий уровень математической подготовки учеников, что зачастую вызывает определенные трудности при изучении материала. Результаты исследований, проведенных психологами В. В. Аавыдовым,

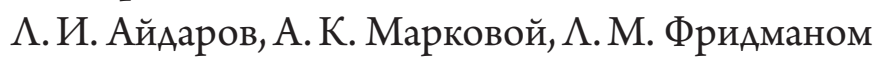
и Ар., Свидетельствуют, что специальное целенаправленное обучение учеников метода моделирования явмяется эффективным средством, которое существенно влияет на характер их учебной Аеятельности: обучение становится более осознанным, целенаправленным и продуктивным.

Понятие математической модели и некоторые общие положения, связанные с ним, Аолжны в той или иной форме имлюстрироваться на протяжении всего курса математики, а разделы школьной программы, посвященные заАачам на работу, Авижение, проценты, прогрессии и, наконец, задачам на применение производных и интегралов, могут рассматриваться как ввеАение в метоА математического моделирования [2].

БАизкая точка зрения по этому вопросу была высказана и самим автором в ходе пеАагогического эксперимента была всесторонне обоснована интегрирующая роль моделирования при реализации межпредметных связей математики и физики и Аоказана эффективность использования многопрофильного преАставления преАметного содержания математики Амя развития познавательного интереса учащихся.

Структура математического моделирования включает в себя ключевые навыки успешного человека XXI столетия. Представим её как совокупность трех взаимосвязанных компонентов: теоретического, практического и мичностного.

Теоретический компонент компетентности математического моделирования преАставляет собой совокупность знаний, веАущими из которых явмяются: научные знания о базовых положений про математическое моделирование, квалификации имеющихся моделей, основных положений теории модекирования и математического моделирования, свойств моделей и соответствующих требований к ним, классификации Аинамических 
систем, особенностей построения математических моделей размичных процессов и явлений, решение Аифференциальных уравнений; теоретические и методологические знания о сути и способы осуществления деятельности в области математического моделирования.

Практический компонент компетентности относительно математического моделирования соАержит рял умений, предусматривающие осуществление математического моделирования в процессе решения практических задач, к которым относятся:

- интемлектуальные умения - понимать прикладные задачи в различных формулировках, находить необходимую информацию ААя их уточнения; выделять отдельные признаки и аспекты целого в процессе составления математической модели; систематизировать, сравнивать, отделять, упорядочивать полученную информацию, делать анализ объектов исследования по определенным признакам; использовать «без машинные» могико-математические категории при составмении уравнений и систем уравнений математической модели, сравнивая наглядные Аанные или воображаемые объекты с их созАанными образами; анализировать динамические процессы, их характеристики и опредемять методы исслеАования; принимать решения и анализировать полученные результаты построения математической модели, отАемяя существенное от второстепенного, закономерное от случайного, общее от еАиничного, качественное от количественного;

- проектировочные умения - составцять планы процесса созАания и исслеАования математической модели объектов, процессов, явлений; строить заАачи, выделять общие и второстепенные цели, входные и выходные характеристики, параметры математической модели; разбивать процесс построения математической модели на отдельные этапы; проектировать математическую модель исследуемого процесса, преАставленную в виде математических формул, знаков, соотношений, операторов; использовать наиболее эффективные и целесообразные математические методы Аля построения модели; применять и совершенствовать имеющиеся алгоритмы по проектированию математической модели и при необходимости разрабатывать новые; применять информационные техномогии в области математического моделирования, специализированные пакеты программ, таких как MATLAB (Simulink) интерпретировать полученные результаты, сравнивать их с первичными целями и целью моделирования и, в случае несоответствия им осуществмять необходимую коррекцию;

- организаторские умения - организовывать Аеятельность по математическому моделированию; подАерживать на Аолжном уровне межличностное общение со всеми участниками процесса построения математической модели исследуемого процесса или явцения;

- коммуникативные умения - скушать и понимать собесеАника, чувствовать и подАерживать обратную связь во время общения по решению прикладной задачи; быстро и правильно ориентироваться в процессе изменений условий общения; использовать в ходе общения в соответствии с ситуацией языковые и невербальные среАства; создавать благоприятную и дружелюбную атмосферу в процессе взаимодействия; вести Аиалог; участвовать в Аискуссиях, убежАать Аругих в правильности своих взгляАОв;

- рефлексивные умения - анализировать собственную деятельность по разработке математических моделей; выявмять недостатки в своей работе по построению, исследования, анамиза математических модемей и на этой основе организовывать самообразование в сфере математического модемирования; проверять достоверность математических методов и уместность их применения при разработке и построения математической модели, определяя свою позицию относительно определенных действий; оценивать результаты деятельности в соответствии с поставленной целью.

\ичностный компонент компетентности с математического моделирования характеризуется 
направленностью мичностных качеств, влияющих на качество Аеятельности по математическому моАелированию, таких как: ответственность, целеустремленность, активность, оптимацьность, инициативность, самостоятельность, толерантность, алекватная самооценка.

ОАнако обнаруженный нами перечень умений математического модемирования, требует некоторого уточнения. Как было показано выше, к умению математического модемирования обычно относят сознательное испомьзование таких мысмительных операций, как анамиз, синтез, обобщение, сравнение, конкретизацию. Аокажем, что эти более элементарные умения явмяются составными частями тех, что выделены в ходе нашего анализа.

1) Умение выдемять главное требует сознательного использования умений анализа, синтеза, абстрагирования и обобщения, сравнения и конкретизации.

2) Умение интерпретировать - расшифровывать язык объекта рассмотрения и умение искать аналогии требует умений анализа и синтеза.

3) Умение классификации. В его основе межит операция Аеления понятия анамиза, синтеза, ин- терпретации, построение причинно-слеАственных связей, обобщение.

4) Компонентами моделирования умение явмяется преАварительный анамиз и перевод (интерпретация) содержания, обобщения.

5) Стратегия как способ Аостижения, хранения и использования информации с целью получения определенного результата предусматривает все вышеперечисленные умения. Ее целью явмяется формирование понятия при минимамьной нагрузки памяти и при условии могического мышиения, аннулирования количества ошибочных Аействий в процессе образования понятия, обеспечение субъективной уверенности в факте его возникновения.

Математическое моделирование - мощный метод познания внешнего мира, прогнозирования и управления. Анализ математической модели позвомяет проникнуть в суть изучаемых явлений. Нет такой сферы жизни и деятемьности человека, гАе бы ни испомьзовались математические модели. История методологии математического модемирования уверяет: она может и Аолжна быть интелмектуамьным яАром информационных технологий всего процесса информатизации общества [1].

\section{Список митературы:}

1. Самарский А.А. Математическое модемирование. ИАеи. Методы. Примеры / А.А. Самарский, А.П. Михайлов.- М.: ФИЗ.-МАТ. АИТ., 2001.- 320 с.

2. Мышкис А. А. О прикладной направленности школьного курса элементов математического анализа [Текст] / А. А. Мышкис / / Математика в школе, 1990.- № 6. - С. 7-11.

3. Волошена В.В. Особливості розвитку умінь математичного моделювання в старшокласників у процесі навчання природничо-математичних предметів / В. В. Волошена / ПеАагогічна освіта: теорія і практика: зб. наук. пр.- Кам'янець-Подімьський, 2016.- Вип. 20 (1-2016),-ч. 1.- С. 261-267.

4. Voloshena V.V. Mathematical modeling as a component integrating physical and mathematical education / V. Voloshena / / Proceedings of the 4th International conference on development of pedagogical science in Eurasia / «East West » Association for Advanced Studies and Higher Education GmbH.-Vienna, 2015.- P. 36-40. 